\title{
Efficacy of Therapeutic Hypothermia for Neurological Salvage in Patients with Cardiogenic Sudden Cardiac Arrest: The Importance of Prehospital Return of Spontaneous Circulation
}

\author{
Takuro Shinada, Noritake Hata, Nobuaki Kobayashi, Kazunori Tomita, \\ Akihiro Shirakabe, Masafumi Tsurumi, Masato Matsushita, Hirotake Okazaki, \\ Yoshiya Yamamoto and Shinya Yokoyama
}

The Division of Intensive Care Unit, Nippon Medical School Chiba Hokusoh Hospital

\begin{abstract}
Aim of the Study: Cardiopulmonary resuscitation and mild therapeutic hypothermia (MTH) have improved neurological outcomes after sudden cardiac arrest, but the factors affecting favorable neurological outcome remain unclear. The aim of this study was to clarify these factors in patients in cardiac arrest treated with MTH.

Methods: Forty-six consecutive patients (mean age, $59.4 \pm 14.3$ years; 37 men and 9 women) who had had cardiogenic cardiac arrest from January 2008 through December 2011, including cases that were and were not shockable, were enrolled in this study, and the factors affecting favorable neurological outcome were retrospectively investigated. The interval from cardiac arrest to cardiopulmonary resuscitation, the return of spontaneous circulation (ROSC), the start of MTH, and the attaining of the target temperature were retrieved from the medical records. The relationship between the neurological outcome and clinical findings, including the causes of cardiac arrest and vital signs before MTH, were also investigated.

Results: Blood pressure and body temperature before MTH were higher, the interval from cardiac arrest to ROSC was shorter, and MTH was started earlier in patients with favorable neurological outcomes than in those with unfavorable outcomes. A multivariate logistic regression model revealed that the presence of prehospital ROSC was predictive of a favorable neurological outcome. In addition, renal failure during MTH occurred more frequently in patients with unfavorable neurological outcomes.

Conclusion: MTH is associated with favorable neurological outcomes after sudden cardiac arrest, including those with non-shockable rhythms, especially in patients with prehospital ROSC.

(J Nippon Med Sch 2013; 80: 287-295)
\end{abstract}

Key words: mild therapeutic hypothermia, neurological outcome, return of spontaneous circulation, sudden cardiac arrest

Correspondence to Noritake Hata, Nippon Medical School Chiba Hokusoh Hospital, 1715 Kamagari, Inzai, Chiba 2701694, Japan

E-mail: hata-n@nms.ac.jp

Journal Website (http://www.nms.ac.jp/jnms/) 


\section{Introduction}

The concept of cardiopulmonary resuscitation (CPR) was standardized by the American Heart Association and the International Liaison Committee on Resuscitation ${ }^{1}$, and the promotion of this concept and the introduction of automated external defibrillators have improved the treatment of patients with sudden cardiac arrest. Although sudden cardiopulmonary arrest is treated by both the emergency medical system and by trained bystanders, the rate of neurologically intact survival remains low. Hypoxic brain damage and infectious complications are associated with death after the return of spontaneous circulation (ROSC); thus, the care given after cardiac arrest is important for avoiding post-cardiac arrest syndrome ${ }^{2}$. On the other hand, mild therapeutic hypothermia (MTH) is an effective method for improving neurological outcomes $^{3,4}$. However, no MTH protocol for optimizing neurological outcomes has been established. Therefore, the present study investigated the factors contributing to favorable neurological outcomes in patients with sudden cardiac arrest treated with MTH.

\section{Patients and Methods}

This study was performed in accordance with the ethical standards of the Declaration of Helsinki, and the study protocol was approved by the Ethics Review Board of Chiba Hokusoh Hospital, Nippon Medical School (approval number 304). All data were retrospectively collected from the medical records. Therefore, written informed consent was not required by the Ethics Review Board, and the concept of the study was disclosed on a poster at our institution. There was no financial support for this study, and there are no conflicts of interest to declare.

\section{Study Population}

Of 113 consecutive patients admitted to an intensive care unit after cardiac arrest from January of 2008 through December of 2011, 46 patients treated with MTH for cardiogenic cardiac arrest were enrolled in this study (Fig. 1). Cases were excluded when the time course of cardiac arrest or CPR procedure was not clear in the medical records. The indications for MTH at our institution are shown in Figure 1. Other exclusion criteria for this study were 1) pregnancy, 2) drug intoxication, 3) bleeding (or bleeding tendency), 4) low daily activity before cardiac arrest, and 5) uncontrollable arrhythmias. The mean age of the enrolled patients was $59.4 \pm 14.3$ years, and 37 of the patients were men. Cardiac diseases were diagnosed with electrocardiography, cardiac ultrasonography, and coronary artery angiography. The underlying diseases leading to sudden cardiac arrest were acute coronary syndrome in 22 patients, other ischemic heart diseases in 10 patients, cardiomyopathy in 7 patients, primary arrhythmias in 4 patients, and others in 3 patients. Percutaneous coronary interventions were performed successfully in 21 of 22 patients with acute coronary syndrome, and these interventions were started after ROSC in all patients and before MTH in 14 patients.

\section{Evaluation of Cardiac Arrest, CPR, and MTH}

Of the 46 cases of cardiac arrest, 43 were out of hospital, and 3 were in hospital. Cardiac arrest was diagnosed by bystanders in 23 cases, by emergency medical technicians in 18 cases, by physicians in 4 cases, and by a critical care nurse in 1 case. The rhythm of cardiac arrest was ventricular fibrillation or pulseless ventricular tachycardia in 39 patients and pulseless electrical activity or asystole in the 7 patients. The timing of the onset of cardiac arrest, the start of CPR, ROSC, hospital arrival, the start of $\mathrm{MTH}$, attaining of target temperature $\left(32^{\circ} \mathrm{C}-34^{\circ} \mathrm{C}\right)$ after MTH, and the termination of MTH were investigated. The intervals were calculated from these time records.

The MTH was administered with a cooling device and self-adhesive, hydrogel-coated pads (Arctic Sun ${ }^{\circledR}$, Medivance, Inc., Louisville, CO, USA) in 34 patients, a cooling blanket (Medi-Therm $\mathrm{II}^{\circledR}$, Gaymar Industries, Inc., Orchard Park, NY, USA) in 10 patients, infusion of cold intravenous fluids in 30 patients, percutaneous cardiopulmonary support 


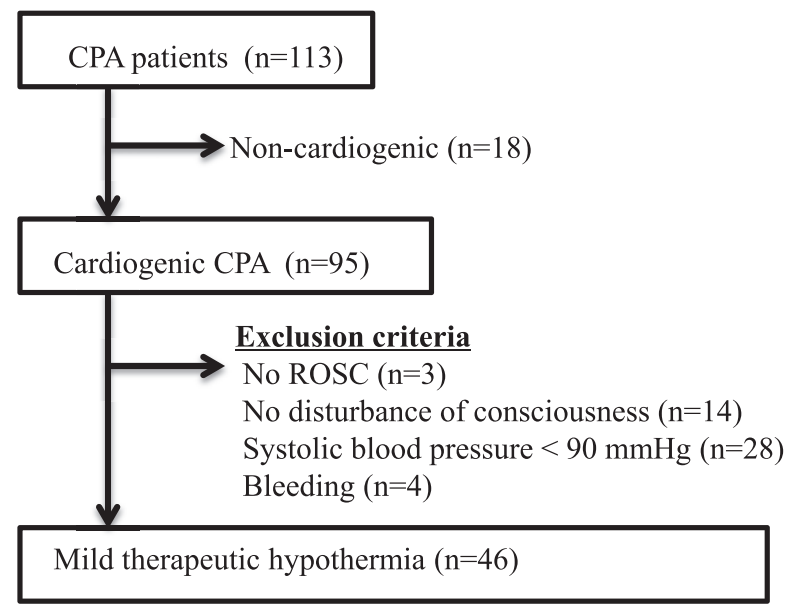

Indication for mild therapeutic hypothermia (meeting all of the following)

1) Age $\geq 15$ years old

2) Cardiogenic cardiac arrest

3) Successful resuscitation ( the presence of ROSC)

4) Persistence of come after ROSC

5) Informed consent from family

6) Systolic blood pressure $\geq 90 \mathrm{mmHg}$ or Mean blood pressure $\geq 60 \mathrm{mmHg}$

Fig. 1 Subjects of this study and indications for mild therapeutic hypothermia at our institution. CPA, cardiopulmonary arrest; ROSC, return of spontaneous circulation

Table 1 Combination of mild therapeutic hypothermia methods

\begin{tabular}{lllllr}
\hline Surface cooling & + & + & + & - & 44 \\
Blood cooling & + & + & - & + & 34 \\
Stomach lavage & + & - & - & - & 7 \\
\hline Number of cases & 7 & 25 & 12 & 2 & 46 \\
\hline Surface cooling includes cooling & blanket & and \\
cooling device with self-adhesive hydrogel-coated \\
pads. Blood cooling includes infusion of cold \\
intravenous fluids and use of a percutaneous \\
cardiopulmonary support system (both in 5 \\
cases).
\end{tabular}

(Bio-Console ${ }^{\circledR}$ 550, Medtronic, Inc., Minneapolis, MN, USA) in 9 patients, and lavage of the stomach in 7 patients (Table 1). The MTH $\left(34^{\circ} \mathrm{C}\right)$ was maintained for 24 to 48 hours, and rewarming was done gradually (over 24 to 72 hours), in accordance with the institutional protocol.

\section{Clinical Findings}

Systolic blood pressure, diastolic blood pressure, heart rate, cardiac rhythm, and body temperature before MTH were investigated. Shock, sepsis, bleeding, pneumonia, seizure, myoclonus, and renal failure were evaluated as complications during MTH.

\section{Neurological Outcome}

The neurological outcome was defined according to the Glasgow-Pittsburgh cerebral performance category (CPC) 30 days after cardiac arrest. ${ }^{5}$. Both CPC-1 (good cerebral performance) and CPC-2 (moderate cerebral disability) were considered favorable neurological outcomes, and CPC-3 (severe cerebral disability), CPC-4 (coma, vegetative state), and CPC-5 (death) were considered unfavorable outcomes. The relationship between neurological outcome and clinical features, including vital signs before MTH and findings during MTH, was investigated.

\section{Statistical Analysis}

All continuous data are expressed as the means \pm standard deviation, and mean differences between 
T. Shinada, et al

Table 2 Time intervals of CPR and MTH

\begin{tabular}{|c|c|c|c|c|c|c|c|}
\hline & \multicolumn{3}{|c|}{ Rhythm of cardia arrest } & \multicolumn{2}{|c|}{ Underlying disease } & \multicolumn{2}{|c|}{ Presence of bystander } \\
\hline & $\begin{array}{l}\text { shockable } \\
\mathrm{n}=39\end{array}$ & $\begin{array}{c}\text { non-shockable } \\
n=7\end{array}$ & & $\begin{array}{c}\text { Ischemic } \\
\text { heart disease } \\
n=32\end{array}$ & $\begin{array}{l}\text { Others } \\
\mathrm{n}=14\end{array}$ & $\begin{array}{c}\text { Bystander } \\
(+) \\
n=29\end{array}$ & $\begin{array}{c}\text { Bystander } \\
(-) \\
n=17\end{array}$ \\
\hline Onset to CPR & $5.2 \pm 5.6$ & $3.3 \pm 6.0$ & & $7.7 \pm 5.9$ & $3.9 \pm 5.2 \uparrow \dagger$ & $1.9 \pm 3.2$ & $10.6 \pm 4.4 \quad \dagger \dagger \dagger$ \\
\hline Onset to ROSC & $32.4 \pm 23.8$ & $51.4 \pm 20.7$ & & $37.4 \pm 24.3$ & $34.4 \pm 24.4$ & $37.4 \pm 26.6$ & $31.7 \pm 19.4$ \\
\hline $\begin{array}{l}\text { Onset to hosptal } \\
\text { arrival }\end{array}$ & $58.9 \pm 51.3$ & $36.6 \pm 18.3$ & & $51.9 \pm 19.1$ & $57.1 \pm 56.8$ & $54.9 \pm 51.4$ & $56.5 \pm 44.0$ \\
\hline $\begin{array}{l}\text { Onset to start of } \\
\text { MHT }\end{array}$ & $151.1 \pm 108.8$ & $210.7 \pm 124.2$ & & $155.2 \pm 102.5$ & $162.3 \pm 117.2$ & $163.4 \pm 110.7$ & $154.6 \pm 117.0$ \\
\hline Onset to $34^{\circ} \mathrm{C}$ & $434.0 \pm 194.3$ & $393.6 \pm 154.7$ & & $361.5 \pm 155.8$ & $456.9 \pm 195.4$ & $437.2 \pm 169.0$ & $411.9 \pm 221.0$ \\
\hline CPR to ROSC & $27.2 \pm 24.8$ & $48.1 \pm 21.3$ & $\dagger$ & $29.6 \pm 25.7$ & $30.8 \pm 25.4$ & $35.9 \pm 26.6$ & $21.1 \pm 20.0$ \\
\hline $\begin{array}{l}\text { CPR to hospital } \\
\text { arrival }\end{array}$ & $53.7 \pm 51.1$ & $33.3 \pm 17.4$ & & $44.2 \pm 20.9$ & $53.4 \pm 56.0$ & $53.3 \pm 51.2$ & $45.9 \pm 43.1$ \\
\hline $\begin{array}{l}\text { CPR to start of } \\
\text { MHT }\end{array}$ & $145.8 \pm 108.9$ & $207.4 \pm 124.9$ & & $147.5 \pm 104.1$ & $158.6 \pm 117.1$ & $161.8 \pm 10.2$ & $144.0 \pm 118.3$ \\
\hline $\mathrm{CPR}$ to $34^{\circ} \mathrm{C}$ & $428.8 \pm 194.4$ & $390.3 \pm 158.8$ & & $353.8 \pm 157.0$ & $453.2 \pm 195.1$ & $435.6 \pm 169.3$ & $401.3 \pm 220.9$ \\
\hline $\begin{array}{l}\text { ROSC to hospital } \\
\text { arrival }\end{array}$ & $26.5 \pm 60.2$ & $-14.9 \pm 16.0$ & & $14.6 \pm 34.9$ & $22.7 \pm 65.5$ & $17.5 \pm 62.0$ & $24.8 \pm 50.8$ \\
\hline $\begin{array}{l}\text { ROSC to start of } \\
\text { MTH }\end{array}$ & $118.6 \pm 103.4$ & $159.3 \pm 107.6$ & & $117.9 \pm 83.3$ & $127.8 \pm 112.7$ & $125.9 \pm 100.3$ & $122.9 \pm 112.8$ \\
\hline ROSC to $34^{\circ} \mathrm{C}$ & $401.6 \pm 195.8$ & $342.1 \pm 165.9$ & & $324.1 \pm 154.9$ & $422.4 \pm 199.7$ & $399.8 \pm 174.6$ & $380.2 \pm 221.5$ \\
\hline $\begin{array}{l}\text { Hospital arrival } \\
\text { to start of MHT }\end{array}$ & $92.1 \pm 106.2$ & $174.1 \pm 115.6$ & & $103.3 \pm 104.7$ & $105.2 \pm 114.5$ & $108.4 \pm 106.5$ & $98.1 \pm 19.8$ \\
\hline $\begin{array}{l}\text { Hospital arrival } \\
\text { to } 34^{\circ} \mathrm{C}\end{array}$ & $375.1 \pm 93.9$ & $357.0 \pm 160.8$ & & $309.6 \pm 155.5$ & $399.8 \pm 196.1$ & $382.3 \pm 171.0$ & $355.4 \pm 217.9$ \\
\hline $\begin{array}{l}\text { Start of MHT to } \\
34^{\circ} \mathrm{C}\end{array}$ & $282.9 \pm 185.3$ & $182.9 \pm 212.6$ & & $206.3 \pm 147.9$ & $294.6 \pm 202.8$ & $273.8 \pm 197.8$ & $257.3 \pm 183.1$ \\
\hline $\begin{array}{l}\text { Prehospital } \\
\text { ROSC, cases (\%) }\end{array}$ & $29(74.4)$ & $1(14.3)$ & $\dagger$ & $21(65.6)$ & $9(64.3)$ & 17 (58.6) & 13 (76.5) \\
\hline
\end{tabular}

Mean \pm standard deviation (minutes); CPR, cardiopulmonary resuscitation; MTH, mild therapeutic hypothermia; ROSC, return of spontaneous circulation; $\uparrow, \mathrm{p}<0.05$ versus shockable; $\uparrow \dagger, \mathrm{p}<0.05$ versus ischemic heart disease; $\dagger \dagger \dagger, \mathrm{p}<0.0001$ versus bystander $(+)$

groups were analyzed with Student's t-test. Proportional differences were analyzed with Fisher's exact analysis. Categorical variables were analyzed with the $\chi^{2}$ test. A multivariate logistic regression model was used to evaluate the factors associated with a favorable neurological outcome. A p value of $<0.05$ was considered to indicate statistical significance. All data were analyzed with the StatView 5 software package for Windows (SAS Institute, Cary, NC, USA) and SPSS $14.0 \mathrm{~J}$ for Windows (SPSS Japan Institute, Tokyo, Japan).

\section{Results}

\section{Time Courses of CPR and MTH}

The time courses of CPR and MTH are shown in Table 2. The interval from the start of CPR to ROSC was shorter in patients with shockable cardiac arrest, and the interval from the onset of cardiac arrest to the start of CPR was shorter in those with ischemic heart disease and those with a bystander present. Prehospital ROSC was significantly more frequent in cases of shockable cardiac arrest (74.4\%) than in cases of non-shockable cardiac arrest (14.3\%). However, there were no 
Therapeutic Hypothermia and Outcome

Table 3 Patient Characteristics

\begin{tabular}{|c|c|c|c|c|c|}
\hline & & $\begin{array}{l}\text { Total } \\
\mathrm{n}=46\end{array}$ & $\begin{array}{c}\text { Favorable neurological } \\
\text { outcome } \\
n=30\end{array}$ & $\begin{array}{l}\text { Unfavorable neurological } \\
\text { outcome } \\
n=16\end{array}$ & $\mathrm{p}$ value \\
\hline Age & (years) & $59.4 \pm 14.3$ & $59.1 \pm 14.6$ & $59.9 \pm 14.1$ & 0.8691 \\
\hline Sex (male/female) & (cases) & $37 / 9$ & $23 / 7$ & $14 / 2$ & 0.3777 \\
\hline \multicolumn{6}{|l|}{ Underlying disease } \\
\hline ischemic heart disease & (cases) & 32 & 21 & 11 & 0.9301 \\
\hline other & (cases) & 14 & 9 & 5 & \\
\hline \multicolumn{6}{|l|}{ Rhythm of cardiac arrest } \\
\hline Vf/pulseless VT & (cases) & 39 & 27 & 12 & 0.1773 \\
\hline others & (cases) & 7 & 3 & 4 & \\
\hline \multicolumn{6}{|l|}{ Presence of bystander } \\
\hline bystander (+) & (cases) & 29 & 20 & 9 & 0.4857 \\
\hline bystander (-) & (cases) & 17 & 10 & 7 & \\
\hline Prehospital ROSC & (cases) & 30 & 25 & 5 & 0.0004 \\
\hline \multicolumn{6}{|l|}{ Interval } \\
\hline Onset to CPR & (min) & $4.9 \pm 5.7$ & $4.9 \pm 6.1$ & $5.0 \pm 5.0$ & 0.9404 \\
\hline Onset to ROSC & $(\min )$ & $35.3 \pm 24.1$ & $24.8 \pm 15.0$ & $55.1 \pm 26.0$ & $<0.0001$ \\
\hline Onset to hospital arrival & $(\min )$ & $55.5 \pm 48.3$ & $63.0 \pm 58.4$ & $41.5 \pm 8.8$ & 0.1525 \\
\hline \multicolumn{6}{|l|}{ Vital sign before MTH } \\
\hline systolic blood pressure & $(\mathrm{mmHg})$ & $134.8 \pm 47.9$ & $147.9 \pm 38.8$ & $110.2 \pm 54.5$ & 0.0092 \\
\hline diastolic blood pressure & $(\mathrm{mmHg})$ & $67.8 \pm 36.1$ & $75.7 \pm 33.4$ & $53.2 \pm 37.4$ & 0.0429 \\
\hline heart rate & (beats/min) & $97.1 \pm 31.9$ & $98.5 \pm 26.3$ & $94.4 \pm 41.3$ & 0.6788 \\
\hline body temperature & $\left({ }^{\circ} \mathrm{C}\right)$ & $35.6 \pm 1.5$ & $36.0 \pm 1.0$ & $34.9 \pm 2.0$ & 0.0217 \\
\hline
\end{tabular}

Vf, ventricular fibrillation; VT, ventricular tachycardia; ROSC, return of spontaneous circulation; CPR, cardiopulmonary resuscitation; MTH, mild therapeutic hypothermia

differences in other intervals, including that from arrest onset to ROSC, in regards to the rhythm of cardiac arrest, underlying diseases, and the presence of a bystander.

\section{Clinical Findings before MTH and Outcome}

The relationship between clinical findings before MTH and neurological outcome is shown in Table 3. Patients with a favorable neurological outcome more often had prehospital ROSC and had higher blood pressures and body temperatures than did patients with an unfavorable outcome. There were no differences in outcome regarding age, sex, underlying disease, or the rhythm of cardiac arrest.

\section{MTH and Outcomes}

Table 4 shows the relationship between the MTH procedure and neurological outcome. The intervals to the start of MTH from the onset of cardiac arrest, the start of CPR, and hospital arrival were significantly shorter in patients with a favorable neurological outcome than in patients with an unfavorable neurological outcome. The time to achieving the target temperature and the duration of MTH had no significant relationship with the outcome.

\section{Complications during MHT}

Complications during MTH are shown in Table 5. Renal failure was significantly more frequent in patients with a poor neurological outcome, but the other complications, including bleeding, shock, pneumonia, seizure, and myoclonus, were not.

\section{Factors Predicting a Favorable Neurological}

\section{Outcome}

A multivariate logistic regression model revealed that prehospital ROSC was predictive of a favorable neurological outcome (Table 6). However, neither systolic blood pressure nor the interval from hospital arrival to the start of MTH predicted a favorable neurological outcome. 
Table 4 Therapeutic hypothermia

\begin{tabular}{|c|c|c|c|c|c|}
\hline & & $\begin{array}{l}\text { Total } \\
\mathrm{n}=46\end{array}$ & $\begin{array}{c}\text { Favorable neurological } \\
\text { outcome } \\
n=30\end{array}$ & $\begin{array}{l}\text { Unfavorable neurological } \\
\text { outcome } \\
n=16\end{array}$ & $\mathrm{p}$ value \\
\hline Onset to start of MTH & (min) & $160.1 \pm 112.0$ & $136.3 \pm 99.0$ & $204.9 \pm 123.8$ & 0.0463 \\
\hline CPR to start of MTH & $(\min )$ & $155.2 \pm 112.2$ & $131.4 \pm 100.1$ & $199.9 \pm 123.1$ & 0.0475 \\
\hline ROSC to start of MTH & $(\min )$ & $124.8 \pm 103.8$ & $111.5 \pm 95.1$ & $149.8 \pm 117.6$ & 0.2371 \\
\hline Hospital arrival to start of MTH & $(\min )$ & $104.6 \pm 110.4$ & $73.3 \pm 88.8$ & $163.4 \pm 125.2$ & 0.0069 \\
\hline Onset to $34^{\circ} \mathrm{C}$ & $(\min )$ & $427.8 \pm 187.9$ & $430.5 \pm 151.7$ & $422.9 \pm 247.7$ & 0.8987 \\
\hline $\mathrm{CPR}$ to $34^{\circ} \mathrm{C}$ & $(\min )$ & $422.9 \pm 188.3$ & $425.6 \pm 151.6$ & $417.9 \pm 248.9$ & 0.8972 \\
\hline ROSC to $34^{\circ} \mathrm{C}$ & $(\min )$ & $392.5 \pm 191.1$ & $405.7 \pm 154.6$ & $367.9 \pm 249.6$ & 0.5289 \\
\hline Hospital arrival to $34^{\circ} \mathrm{C}$ & $(\min )$ & $372.3 \pm 187.7$ & $367.5 \pm 150.1$ & $381.4 \pm 249.1$ & 0.8131 \\
\hline Start of MHT to $34^{\circ} \mathrm{C}$ & $(\min )$ & $267.7 \pm 190.6$ & $294.2 \pm 149.1$ & $218.1 \pm 249.0$ & 0.2004 \\
\hline Duration of MTH & $(\min )$ & $1,560.5 \pm 406.9$ & $1,617.8 \pm 342.2$ & $1,453.1 \pm 501.5$ & 0.1942 \\
\hline
\end{tabular}

$\mathrm{MTH}$, mild therapeutic hypothermia; CPR, cardiopulmonary resuscitation; ROSC, return of spontaneous circulation

Table 5 Complications during mild therapeutic hypothermia

\begin{tabular}{lccccc}
\hline & & $\begin{array}{c}\text { Total } \\
\mathrm{n}=46\end{array}$ & $\begin{array}{c}\text { Favorable neurological } \\
\text { outcome } \\
\mathrm{n}=30\end{array}$ & $\begin{array}{c}\text { Unfavorable neurological } \\
\text { outcome } \\
\mathrm{n}=16\end{array}$ & $\mathrm{p}$ value \\
\hline Bleeding & (cases) & 3 & 1 & 2 & 0.2304 \\
Seizure & (cases) & 3 & 1 & 2 & 0.2304 \\
Myoclonus & (cases) & 2 & 2 & 0 & 0.2910 \\
Shock & (cases) & 3 & 1 & 2 & 0.2304 \\
Renal failure & (cases) & 6 & 1 & 5 & 0.0074 \\
Pneumonia & (cases) & 13 & 10 & 3 & 0.2955 \\
\hline
\end{tabular}

Table 6 Multivariate analysis of factors associated with a favorable neurological outcome

\begin{tabular}{lccc}
\hline & \multicolumn{3}{c}{ Favorable neurological outcome } \\
\cline { 2 - 4 } & Odd ratio & 95\% confidence interval & $\mathrm{p}$ value \\
\hline Prehospital ROSC & 7.8482 & $0.5006-3.6199$ & 0.0096 \\
Hospital arrival to start of MHT $(\leq 60 \mathrm{~min})$ & 4.0636 & $-0.2366-3.0407$ & 0.0935 \\
Systolic blood pressure before MTH $(\geq 140 \mathrm{mmHg})$ & 3.1209 & $-0.5966-2.8728$ & 0.1985 \\
Body temperature before MTH $\left(\geq 36^{\circ} \mathrm{C}\right)$ & 1.8203 & $-1.2711-2.4691$ & 0.5302 \\
\hline
\end{tabular}

ROSC, return of spontaneous circulation; MTH, mild therapeutic hypothermia

\section{Discussion}

\section{Effects of MTH and Cardiac Arrest Rhythm}

The first case report of MTH after cardiac arrest was published by Williams et al. in $1958^{6}$. They reported that 4 patients had a favorable neurological outcome after cardiac arrest and resuscitation with $\mathrm{MTH}$ induced by surface cooling $\left(30^{\circ} \mathrm{C}-34^{\circ} \mathrm{C}\right)$ for 24 to 72 hours. Thereafter, several reports of $\mathrm{MTH}$ were published ${ }^{7-9}$. The concept of CPR was standardized by the American Heart Association and the International Liaison Committee on Resuscitation in $2000^{1}$, and the recovery of neurological damage is a highlight of care after cardiac arrest ${ }^{2,1011}$. The beneficial effects of MTH are significant for patients with shockable cardiac arrest (ventricular fibrillation or pulseless ventricular tachycardia) ${ }^{2,12,13}$, but, according to recent reports, MTH is also beneficial in patients with nonshockable cardiac arrest (pulseless electrical activity or asystole $)^{2.14-16}$. The present study suggests that the 
effects of MTH on neurological outcome are not correlated with the rhythm of cardiac arrest. Soga et al. have reported that MTH is effective in nonshockable cardiac arrest when ROSC occurs less than 16 minutes after cardiac arrest ${ }^{16}$, but ROSC was late in our study population $(32.4 \pm 23.8$ minutes in shockable cardiac arrest and $51.4 \pm 20.7$ minutes in non-shockable cardiac arrest).

\section{CPR Procedure and Neurological Outcome}

A shorter interval from cardiac arrest to ROSC is a factor predicting a favorable neurological outcome $^{17,18}$. However, Testori et al have reported that the beneficial effect of MTH increases with the cumulative time of complete circulatory standstill in patients with witnessed out-of-hospital cardiac arrest (late ROSC) $^{19}$; so, there should be no hesitation in administering MTH in cases with late ROSC. In the findings of the present study, patients with early ROSC had a favorable neurological outcome, especially those with prehospital ROSC. On the other hand, in the present study the interval from cardiac arrest to the start of CPR did not affect the neurological outcome. These findings suggest that the effects of CPR are strongly related to the CPR skill of bystanders and emergency medical staff before hospital arrival; so, there is no relationship between the neurological outcome and the interval from cardiac arrest to the start of CPR.

\section{Vital Signs before MTH and Neurological Outcome}

Spontaneous hypothermia is a factor associated with an unfavorable neurological outcome, and the time to achieve the target temperature is shorter and the rewarming time is longer in such cases than in cases with normal body temperature ${ }^{20.21}$. The present study also found that body temperature before MTH was lower in patients with unfavorable neurological outcomes but that the time from the start of MTH to achieving the target temperature did not differ between patients with favorable outcomes and those with unfavorable outcomes, because spontaneous hypothermia was recognized in few cases. There was no evidence of a relationship between any vital sign and neurological outcomes ${ }^{22}$, but the guidelines for treating sudden cardiac arrest recommend that the systolic blood pressure be maintained at $90 \mathrm{~mm} \mathrm{Hg}$ or greater ${ }^{2}$. In the present series the blood pressure was higher in patients with a favorable neurological outcome than in those with a poor outcome.

\section{Procedure of MTH and Neurological Outcome}

An early start of MTH was associated with a favorable neurological outcome in the present study, but the Italian Cooling Experience Study Group has reported that an early start of MTH did not affect the outcome ${ }^{23}$. The interval from the onset of cardiac arrest to the start of MTH may have been shorter in patients with a favorable neurological outcome in the present study because the start of MTH was early in cases with early ROSC. On the other hand, the time to achieving the target temperature and the duration of MTH did not affect the outcome, a finding that is consistent with previous reports ${ }^{24,25}$.

\section{Complications during MTH and Neurological} Outcome

In the present study renal dysfunction during MTH was associated with an unfavorable neurological outcome. Vanstan et al have reported that acute kidney injury is a risk factor for a poor neurological outcome in patients after sudden cardiac arrest ${ }^{26}$. However, the present study found no relationship between neurological outcome and other complications, including bleeding, shock, pneumonia, seizure, and myoclonus, during MTH.

\section{Other Clinical Findings and Neurological Outcome}

Belliard et al have reported that older patients tended to have unfavorable neurological outcomes ${ }^{18}$, but in the present study we found no relationship between age and neurological outcome. We also found no difference in outcome between patients with ischemic heart disease and those with other underlying diseases. Because of the small number of patients, the efficacy of early coronary reperfusion could not be analyzed in the present study. 


\section{Study Limitations}

First, this study included a small number of patients with cardiogenic cardiac arrest and was performed retrospectively in only a single university hospital. Second, various MTH procedures were used, and the differences between them could not be precisely analyzed. A large, prospective, multicenter cohort study is recommended to clarify the relation of outcome to the status of cardiac arrest, vital signs before MTH, complications during MTH, and medications, in patients with sudden cardiac arrest.

\section{Conclusions}

The present study has found that MTH is associated with favorable neurological outcomes after sudden cardiac arrest, including those with non-shockable rhythms. Earlier ROSC, especially prehospital ROSC, predicts a favorable neurological outcome in patients treated with MTH after sudden cardiogenic cardiac arrest. Poor renal function during MTH is a factor predicting an unfavorable neurological outcome.

Conflict of Interest: The authors have no conflicts of interest to declare.

Funding: There was no financial funding.

Acknowledgement: We thank the staff of critical care medicine, the intensive care unit, and the emergency medical service for their care of patients. We also thank the staff of the medical records office for their valuable assistance.

\section{References}

1. Guidelines 2000 for Cardiopulmonary Resuscitation and Emergency Cardiovascular Care. Part 3: adult basic life support. The American Heart Association in collaboration with the International Liaison Committee on Resuscitation. Circulation 2000; 102 (Suppl): I22-I59.

2. Peberdy MA, Callaway CW, Neumar RW, et al.: Part 9: post-cardiac arrest care: 2010 American Heart Association Guidelines for Cardiopulmonary Resuscitation and Emergency Cardiovascular Care. Circulation 2010; 122(Suppl 3): S768-S786.

3. Mild therapeutic hypothermia to improve the neurologic outcome after cardiac arrest. N Engl J Med 2002; 346: 549-556.

4. Bernard SA, Gray TW, Buist MD, et al.: Treatment of comatose survivors of out-of-hospital cardiac arrest with induced hypothermia. N Engl J Med 2002; 346: 557-563.

5. Cummins RO, Chamberlain DA, Abramson NS, et al: Recommended guidelines for uniform reporting of data from out-of-hospital cardiac arrest: the Utstein Style. A statement for health professionals from a task force of the American Heart Association, the European Resuscitation Council, the Heart and Stroke Foundation of Canada, and the Australian Resuscitation Council. Circulation 1991; 84: 960-975.

6. Williams GR Jr, Spencer FC: The clinical use of hypothermia following cardiac arrest. Ann Surg 1958; 148: 462-468.

7. Benson DW, Williams GR Jr, Spencer FC, Yates AJ: The use of hypothermia after cardiac arrest. Anesth Analg 1959; 38: 423-428.

8. Ravitch MM, Lane R, Safar P, Steichen FM, Knowles P: Lightning stroke. Report of a case with recovery after cardiac massage and prolonged artificial respiration. N Engl J Med 1961; 264: 36-38.

9. Safar P: On the history of modern resuscitation. Crit Care Med 1996; 24(Suppl): S3-11.

10. 2005 American Heart Association Guidelines for Cardiopulmonary Resuscitation and Emergency Cardiovascular Care. Circulation 2005; 112(Suppl): IV1-203.

11. Neumar RW, Nolan JP, Adrie C, et al: Post-cardiac arrest syndrome: epidemiology, pathophysiology, treatment, and prognostication. A consensus statement from the International Liaison Committee on Resuscitation (American Heart Association, Australian and New Zealand Council on Resuscitation, European Resuscitation Council, Heart and Stroke Foundation of Canada, InterAmerican Heart Foundation, Resuscitation Council of Asia, and the Resuscitation Council of Southern Africa); the American Heart Association Emergency Cardiovascular Care Committee; the Council on Cardiovascular Surgery and Anesthesia; the Council on Cardiopulmonary, Perioperative, and Critical Care; the Council on Clinical Cardiology; and the Stroke Council. Circulation 2008; 118: 2452-2483.

12. Arrich J: Clinical application of mild therapeutic hypothermia after cardiac arrest. Crit Care Med 2007; 35: 1041-1047.

13. Storm C, Nee J, Roser M, Jorres A, Hasper D: Mild hypothermia treatment in patients resuscitated from non-shockable cardiac arrest. Emerg Med J 2012; 29: 100-103.

14. Testori C, Sterz F, Behringer W, et al.: Mild therapeutic hypothermia is associated with favourable outcome in patients after cardiac arrest with non-shockable rhythms. Resuscitation 2011; 82: $1162-1167$

15. Lundbye JB, Rai M, Ramu B, et al.: Therapeutic hypothermia is associated with improved neurologic outcome and survival in cardiac arrest survivors of non-shockable rhythms. Resuscitation 2012; 83: 202207.

16. Soga T, Nagao K, Sawano H, et al.: Neurological benefit of therapeutic hypothermia following return of spontaneous circulation for out-of-hospital nonshockable cardiac arrest. Circ J 2012; 76: 2579-2585.

17. Oddo M, Schaller MD, Feihl F, Ribordy V, Liaudet L: 
From evidence to clinical practice: effective implementation of therapeutic hypothermia to improve patient outcome after cardiac arrest. Crit Care Med 2006; 34: 1865-1873.

18. Belliard G, Catez E, Charron C, et al.: Efficacy of therapeutic hypothermia after out-of-hospital cardiac arrest due to ventricular fibrillation. Resuscitation 2007; 75: 252-259.

19. Testori C, Sterz F, Holzer M, et al:: The beneficial effect of mild therapeutic hypothermia depends on the time of complete circulatory standstill in patients with cardiac arrest. Resuscitation 2012; 83: 596-601.

20. Benz-Woerner J, Delodder F, Benz R, et al: Body temperature regulation and outcome after cardiac arrest and therapeutic hypothermia. Resuscitation 2012; 83: 338-342.

21. Lyon RM, Richardson SE, Hay AW, Andrews PJ, Robertson CE, Clegg GR: Esophageal temperature after out-of-hospital cardiac arrest: an observational study. Resuscitation 2010; 81: 867-871.

22. Gaieski DF, Neumar RW, Fuchs B, et al: Haemodynamic management strategies are not explicitly defined in the majority of therapeutic hypothermia implementation studies. Resuscitation
2012, doi: 10.1016/j.resuscitation.2011.12.016.

23. Early- versus late-initiation of therapeutic hypothermia after cardiac arrest: Preliminary observations from the experience of 17 Italian intensive care units. Resuscitation 2011, doi: 10.1016/ j.resuscitation.2011.12.002.

24. Haugk M, Testori C, Sterz F, et al.: Relationship between time to target temperature and outcome in patients treated with therapeutic hypothermia after cardiac arrest. Crit Care 2011; 15: R101.

25. Lyon RM, Robertson CE, Clegg GR: Therapeutic hypothermia in the emergency department following out-of-hospital cardiac arrest. Emerg Med J 2010; 27: 418-423.

26. Vanston VJ, Lawhon-Triano M, Getts R, Prior J, Smego RA Jr: Predictors of poor neurologic outcome in patients undergoing therapeutic hypothermia after cardiac arrest. South Med J 2010; 103: 301-306.

(Received, July 28, 2012)

(Accepted, March 8, 2013) 